\title{
EPISÓDIOS MARCANTES DAS AULAS DE EDUCAÇÃO FÍSICA: VALORIZANDO AS EXPERIÊNCIAS DOS ALUNOS POR MEIO DE NARRATIVAS
}

IMPORTANT EPISODES OF PHYSICAL EDUCATION CLASSES: VALUING STUDENTS' EXPERIENCES THROUGH NARRATIVES

EPISODIOS DESTACADOS DE LAS CLASES DE EDUCACIÓN FÍSICA: VALORIZANDO LAS EXPERIENCIAS DE LOS ALUMNOS A TRAVÉS DE NARRATIVAS

\author{
Eliane Isabel Fabri*, Fernanda Rossi, Lilian Aparecida Ferreira*
}

Palavras-chave

Aprendizado baseado em

problemas.

Ensino fundamental

e médio.

Narração.
Resumo: A escola, lugar no qual os estudantes passam um tempo considerável e intenso de relações, se constitui como um cenário de possibilidades de construção de experiências. Este estudo buscou identificar e analisar os episódios, em formato de casos de ensino, escritos por alunos do ensino médio sobre suas experiências nas aulas de Educação Física. As experiências narradas pelos alunos trouxeram indagações aos professores de Educação Física no sentido de mobilizar o saber orgânico para um saber verbalizado, constituindo com isso uma pedagogia que reconheça efetivamente a experiência discente como um saber.

\section{Keywords} Problem-based learning. Primary and secondary education. Narration.

Palabras clave Aprendizaje basado en problemas. Educación primaria y secundaria. Narración.
Abstract: School - where students spend considerable time and live intense relationships - is a scenario of possibilities for experience-building. This study aimed to identify and analyze episodes written by high school students about their experiences in Physical Education classes, in the format of teaching cases. The experiences narrated by the students raised questions to Physical Education teachers by mobilizing organic knowledge towards verbalized knowledge, thus establishing a pedagogy that effectively recognizes students' experience as knowledge.

Resumen: La escuela, el lugar donde los estudiantes pasan un tiempo considerable e intenso de relaciones, se constituye como un escenario de posibilidades de construcción de experiencias. Este estudio tuvo como objetivo identificar y analizar los episodios en la forma de casos de enseñanza, escritos por estudiantes de secundaria acerca de sus experiencias en las clases de Educación Física. Las experiencias narradas por los alumnos trajeron preguntas a los profesores de Educación Física en el sentido de movilizar el saber orgánico hacia un conocimiento verbalizado, formando con ello una pedagogía que reconozca efectivamente la experiencia de los estudiantes como un saber.
* Universidade Estadual Paulista "Júlio de Mesquita Filho". Bauru, SP, Brasil. E-mail: lia_fabri@hotmail.com

Recebido em: 30-06-2015 Aprovado em: 13-01-2016 (c) (i) () Licence 


\section{INTRODUÇÃO}

Segundo Perrenoud (1995), a escola é para o aluno um meio de vida social cheio de valores, complexo e ativo. Local onde os alunos passam grande parte do seu dia, se relacionando com outros que são parecidos ou completamente diferentes, aprendem coisas que vão além dos conteúdos escolares, demonstram todos os tipos de sentimentos, atitudes, comportamentos.

Essas intensas relações sociais se assentam numa longa temporalidade, ou seja, um aluno que ingressa na educação infantil, depois ensino fundamental e, posteriormente, ensino médio, passa aproximadamente de 12 a 14 anos dentro da instituição escolar. Inegavelmente esse tempo está nutrido por uma série de elementos que vão construindo suas percepções sobre o mundo, a vida, o outro e si mesmo: experiências.

O conceito de experiência discutido no presente artigo está fundamentado na concepção de Larrosa Bondía $(2002,2011)$. O filósofo espanhol se propõe "[...] a pensar a educação a partir do par experiência/sentido" (LARROSA BONDÍA, 2002, p. 19, grifos do autor). 0 autor afirma que a palavra experiência tem sido usada muitas vezes de modo banal, sem consciência de suas inúmeras possibilidades no campo da educação. Define experiência como aquilo "[...] que nos passa, o que nos acontece, o que nos toca". Ou seja, não se trata de qualquer acontecimento, mas aquele que nos modifica, nos permite construir e reconstruir sentidos. 0 sujeito da experiência confere sentido não às atividades em si, mas pela transformação do acontecimento em experiência, pois, como complementa o autor, experiência não é apenas 0 que se passa, o que acontece ou o que toca, já que "[...] a cada dia se passam muitas coisas, porém, ao mesmo tempo, quase nada nos acontece" (LARROSA BONDÍA, 2002, p. 21).

Desse modo, a experiência é algo que nos acontece e o modo como lhe atribuímos sentido. "A experiência e o saber que dela deriva são o que nos permite apropriar-nos de nossa própria vida" (LARROSA BONDÍA, 2002, p. 27). Nesse âmago, o sujeito da experiência "[...] seria algo como um território de passagem, algo como uma superfície sensível que aquilo que acontece afeta de algum modo, produz alguns afetos, inscreve algumas marcas, deixa alguns vestígios, alguns efeitos" (LARROSA BONDÍA, 2002, p.24) e ainda que o acontecimento "[...] afeta a mim, que produz efeitos em mim, no que eu sou, no que eu penso, no que eu sinto, no que eu sei, no que eu quero, etc." (LARROSA BONDÍA, 2011, p. 7).

Larrosa Bondía (2002) enfatiza que todos os dias se passam muitas coisas, porém, ao mesmo tempo, são poucos os acontecimentos marcantes. Isso porque o modo como as coisas estão organizadas contribui para que as experiências não ocorram, afirma ancorado em Walter Benjamin. A pobreza de experiências que caracteriza o mundo atual, marcado pelo excesso de informação, a obrigatoriedade de ter opinião sobre todas as coisas que se passam e 0 excesso de trabalho, elementos que combinados com a falta de tempo caracterizam a vida contemporânea, diminuindo as possibilidades de construir experiências: "[...] nunca se passaram tantas coisas, mas a experiência é cada vez mais rara" (LARROSA BONDÍA, 2002, p. 21).

Partindo desta perspectiva, tais experiências marcam ações, revelam sentimentos, explicitam desafios, demarcam resistências, apontam superações. A abertura a este universo das coisas que nos afetam nos ajuda a efetivamente reconhecer os alunos como participantes ativos da produção do saber escolar e a experiência como acontecimento que ultrapassa a 
superficialidade de uma mera atividade que poderia se configurar como algo passageiro na vida do aluno.

Aliás, um saber escolar que se faz desde o corpo, do contato do aluno com as experimentações sobre o/do mundo e seus processos de significação, evidenciando uma realidade encarnadamente construída nas aulas de Educação Física. Nas palavras de MarielRuiz (2010, p. 5): "De ese modo, saber y experiencia se entrelazan en una relación de mutua reciprocidad y empatía que no puede quedar al margen de ninguna práctica pedagógica y mucho menos de la práctica pedagógica de la educación física".

Em tais cenários podem ser revelados episódios marcantes que evidenciem experiências positivas e negativas na relação dos discentes com este componente curricular. Para dar visibilidade a tais episódios, nossa proposta se assentou nas narrativas em formato de casos de ensino.

Caracterizando os casos de ensino, Nono e Mizukami (2002) os definem como sendo histórias onde se combinam descrições de acontecimentos, reflexões e conceitos teóricos que permitem fundamentar os episódios descritos. Estruturalmente são reconhecidos como um registro de um episódio ou acontecimento escolar, uma história narrada em primeira pessoa contada em detalhes que contenha informações sobre o contexto e sobre os personagens envolvidos e que permita diferentes análises.

O propósito da elaboração dos casos de ensino por parte dos alunos está em ampliar as formas de utilização e empreendimento das narrativas escritas na pesquisa em educação, revelando que os alunos, assim como os professores (personagens mais comuns nas construções/apropriações dos casos de ensino), também têm muito a nos dizer e, portanto, podem nos ajudar a compreender melhor o cenário da educação escolar, configurando-se como um instrumento que permite destacar, compreender e valorizar o papel da experiência na formação escolar. Segundo Larrosa Bondía (2002, p. 19-20), "[...] as palavras produzem sentido, criam realidades e, às vezes, funcionam como potentes mecanismos de subjetivação".

Considerando que os casos de ensino são recursos profícuos para fazer emergir episódios marcantes, resultantes de experiências que conferem sentido ao que acontece ao sujeito, o objetivo da presente pesquisa foi identificar e analisar os episódios, em formato de casos de ensino, escritos por alunos do ensino médio sobre suas experiências nas aulas de Educação Física.

\section{PERCURSO METODOLÓGICO}

Ganhou relevo na pesquisa o ponto de vista do sujeito investigado, bem como as interfaces entre pesquisador e sujeito no sentido de captar com a maior fidedignidade possível seu modo de olhar e se relacionar com o mundo. Tais elementos incluem a pesquisa em questão na abordagem qualitativa de investigação de acordo com Bogdan e Biklen (1994).

O instrumento de coleta empreendido foi a narrativa escrita em formato de caso de ensino. De acordo com Reis (2008) a investigação narrativa nutre-se por uma valorização da subjetividade articulada à compreensão da realidade, "[...] convidando os investigados a falarem acerca de si próprios, dando-Ihes a palavra" (REIS, 2008, p. 22). No universo das narrativas, as possibilidades são inúmeras, desde sua natureza oral ou escrita, até as suas 
várias peculiaridades como: história de vida, diários de aula, entrevista em profundidade, biografias, trajetórias pessoais e os casos de ensino.

Assim, acessar o pensamento do sujeito por meio da escrita, como defende Zabalza (2004), é um recurso bastante positivo para dar evidência às formas de racionalidade e da expressão pessoal de quem escreve.

A pesquisa in loco teve início em março de 2011 em duas escolas públicas, com visitas semanais da pesquisadora, totalizando nove meses de permanência no campo.

Os sujeitos participantes do estudo foram alunos jovens do ensino médio, selecionados para a pesquisa por terem vivido um tempo significativo na escola, o que poderia lhes possibilitar maior trânsito na temporalidade e diversidade de suas lembranças sobre as aulas de Educação Física.

Os jovens envolvidos e também seus responsáveis assinaram o termo de assentimento e consentimento, autorizando a realização do estudo. Tal processo foi autorizado institucionalmente pelo Comitê de Ética em Pesquisa em 20/10/2010 - processo no. 10495/46/01/10.

Ao longo de um semestre a pesquisadora esteve nas aulas de Educação Física aproximando-se da realidade escolar e dos alunos, construindo vínculos afetivos, pois, como conceitua Galvão (2005), o uso das narrativas como metodologia carrega consigo uma intromissão na vida de outra pessoa - uma legítima exposição do eu - uma vez que "[...] nós somos, pelo menos parcialmente, constituídos pelas histórias que contamos aos outros e a nós mesmos acerca das experiências que vamos tendo" (GALVÃO, 2005, p. 330).

Depois dessa aproximação inicial, a pesquisadora ainda permaneceu mais três meses nas instituições convidando os alunos para a produção dos casos de ensino. Nesta interação, eram oferecidas orientações sobre como produzir uma narrativa em formato de caso de ensino, incentivando os alunos a contarem episódios que, de fato, revelassem suas trajetórias pessoais ou ocorrências marcantes por eles observadas em suas aulas de Educação Física.

Com o intuito de ampliar as compreensões acerca das narrativas coletadas, a pesquisadora entrevistou cada participante, questionando sobre que tipo de experiência aquela situação havia Ihe despertado, se ela havia contribuído para uma aproximação ou distanciamento para com as aulas de Educação Física na escola e em qual ano escolar tal situação havia ocorrido.

Os dados foram analisados a partir de uma leitura intensa que cotejou os episódios construídos, as respostas dos alunos manifestadas nas entrevistas e a articulação com autores que favoreceram o diálogo com a temática.

Como sugere Zabalza (2004, p.151) na análise de narrativas escritas, "[...] o que está em jogo [...] não é a qualidade da produção, mas sua riqueza expressiva". Segundo Scott (2001, p. 46), "escribir es la reproducción, la transmisión y la comunicación del conocimiento obtenido mediante la experiencia (visual y visceral)".

Para dar visibilidade na íntegra aos casos de ensino produzidos pelos alunos, foi necessário realizar uma seleção que pudesse garantir suas particularidades, bem como utilizar adequadamente o espaço disponível para a apresentação do artigo estabelecido por este periódico. Neste sentido, embora tenham sido coletados 20 episódios, cinco foram apresentados e analisados neste texto. Destes episódios emergiram três eixos de análise que 
serão problematizados a seguir, são eles: a) experiência negativa resultando em fracasso; b) experiência negativa resultando em mais participação nas aulas; c) experiência positiva resultando em mais participação nas aulas.

\section{A PRODUÇÃO DE EXPERIÊNCIAS NAS AULAS DE EDUCAÇÃO FÍSICA}

Para Larrosa Bondía (2002), as experiências nos marcam e, ao nos marcarem, estabelecem processos de sentidos para a nossa vida. 0 autor dá como exemplo a leitura de um livro que, para a Educação Física, poderia ser a participação do aluno em um jogo. Não se trata de saber o que acontece no jogo e nem o que eu penso sobre o jogo, mas como posso me formar ou me transformar na relação que estabeleço no jogo. 0 importante, neste sentido, é que no processo de formação ou transformação eu passe "[...] a pensar por mim mesmo, em primeira pessoa, com minhas próprias ideias" (LARROSA BONDÍA, 2002, p. 11), ou ainda, eu possa sentir por mim mesmo. Ter jogado, entretanto, não garante que se tenha alguma experiência. 0 jogo pode ser uma ação repetida ou rotineira e que não traga qualquer marca ao aluno.

Larrosa Bondía (2002) ressalta que a experiência na escola tem sido cada vez mais rara por falta de tempo, pois os currículos escolares estão mais volumosos, em termos de disciplinas e conteúdos, e com pouco tempo para seu desenvolvimento. Tal aceleração e a superficialidade do tempo escolar têm feito da escola espaço gerador de pouca experiência, já que muitas coisas tem se passado e não nos passado. Entretanto, as experiências que são construídas podem gerar aproximações, indiferenças e distanciamentos com professores, com conteúdos, com colegas da escola, com lugares na sala, etc. Tais construções podem resultar em cenários de dificuldade de aprendizagem e reprovação, sinalizando para o que muitos identificam como fracasso escolar. Ao contrário disso, existe a possibilidade de gerar interesse, envolvimento, curiosidade, dando condições para uma aprendizagem mais efetiva, autonomia, domínio, aprovação, sucesso escolar.

Para Nutti e Reali (2002), o fracasso escolar não pode ser reduzido somente à repetência escolar ou reprovação do aluno "[...] mas à situação em que o aluno, em seu cotidiano escolar, não pensa a partir das suas próprias elaborações mentais e não se sente autorizado a expressar o seu próprio pensamento" (NUTTI; REALI, 2002, p. 22). Como seria transferirmos estas reflexões para as aulas de Educação Física? O que seria uma situação de fracasso?

No universo da Educação Física Escolar a matriz de construção de muitas das experiências em aula se dá pelo corpo e pelo movimento, na medida em que se trata de um componente curricular que envolve o sentir, o pensar e 0 agir de modo simultâneo. Tais experiências se efetivam num cenário de grande exposição do aluno. Suas fragilidades, seus medos, suas dificuldades, assim como suas conquistas, desenvoltura, facilidades são apresentadas publicamente. Por conta disso, concordamos com Costa $(1997)^{1}$ quando aponta que, no ensino médio:

O aluno, nessa faixa etária, possui uma opinião formada sobre a Educação Física baseada em suas experiências pessoais. Se essas experiências foram marcadas por sucesso e prazer, teremos uma opinião favorável quanto a frequentar as aulas

1 COSTA, Caio Martins. Educação Física diversificada: uma proposta de participação. In: SEMINÁRIO DE EDUCAÇÃO FÍSICA ESCOLAR 4., 1997, Anais... São Paulo: EEFEUSP, 1997. 
de Educação Física no $2^{\circ}$ grau [ensino médio]. Quando o aluno registrou várias situações de insucesso, e de alguma forma se excluiu ou foi excluído, sua opção será pela dispensa das aulas, com um primeiro discurso pautado em não gostar da atividade. Essa postura aponta para quem não quer assumir uma dificuldade pessoal, que passa a ser, quando assumida, substituída por outro discurso, o do "não levo jeito", que em muitas vezes é reforçado pela própria postura do professor, ao eleger algumas práticas como opção de trabalho, em detrimento de outras (COSTA, 1997, p. 47, grifo do autor).

Para a Educação Física, a partir dessas perspectivas, uma experiência negativa poderia resultar em fracasso e ser caracterizada pelo distanciamento do aluno das aulas, ou seja, aquele aluno que, embora sempre esteja presente nas aulas, nunca se envolve com as atividades concretas de vivências propostas pelo professor ou pelos colegas. Muitas vezes ele fica na arquibancada da quadra sozinho, enviando ou vendo mensagem de celular, com fones nos ouvidos apreciando alguma música, conversando com colegas que também não fazem a aula, se justificando que não irá fazer aula, por exemplo, porque está com roupas e/ou calçados inadequados para a atividade proposta etc.

A partir disso podemos reformular o conceito anteriormente apresentado por Nutti e Reali (2002) ao afirmarmos que o fracasso escolar na Educação Física se relaciona ao fato de o aluno não se movimentar e não se sentir autorizado a expressar seu próprio movimento. Ao contrário disso, as experiências positivas poderiam conduzir ao sucesso escolar na Educação Física, que estaria relacionado ao interesse efetivo em participar das vivências de movimento proporcionadas pelas aulas, construindo referências corporais que poderiam incentivar a prática de atividades corporais na escola e fora dela, nos espaços de lazer, em grupos de treinamento etc.

Embora para Larrosa Bondía (2011) a experiência se mostre a partir das dimensões do acontecimento (subjetividade, alteridade e alienação), do sujeito (reflexividade, subjetividade e transformação) e do movimento (passagem e paixão), tais características parecem não convergir para a atual dinâmica da escola, que, segundo o autor, vem contribuindo para inviabilizar que algo nos aconteça.

Diante desse apontamento, surge o desafio de pensar a escola no diálogo com o saber da experiência dos discentes. Saber este que, ainda que pessoal, seria importante passar por um processo de reflexão, considerando que o processo de aprendizagem envolve elementos reflexivos, subjetivos e de transformação.

Essa defesa também é feita por Domingo Contreras (2010), ainda que tenha dado enfoque à ação docente, ao dizer que a subjetividade não pode ser abandonada pela indagação. 0 mesmo nós podemos dizer das experiências dos alunos, mobilizando reflexões que os ajudem a compreender o sentido das coisas que vivem ( $O$ que isso significa para mim? O que faz isso em mim? O que faço agora com isso que vivi?), já que estamos falando de um processo formal de ensino e de uma organização pedagógica.

Como aponta Bracht (1999), as experiências das práticas motrizes passam pelo corpo e por ele são significadas, mas nem sempre conseguem ser transmitidas em palavras. Parece que a palavra é a simplificação das coisas que sentimos, por isso nem sempre conseguimos, por meio dela, manifestar nossas emoções e percepções.

Daí a importância de trabalharmos com o universo das significações ou, como propôs Betti, (1994) com a 
[...] "leitura" dos "signos" relacionados à sua prática corporal de movimento: esta intensidade e modalidade de atividade corporal foram boas para mim? fizeramme sentir bem? foram significativas para mim? foram prazerosas? fatiguei-me? quais as características da estrutura da atividade que posso relacionar ao meu bem estar ou fadiga? quais são, para mim, os sinais de fadiga? que condições a sociedade em que vivo oferece para se praticar esta atividade? quais são os grupos sociais interessados nesta prática? (BETTI, 1994, p. 42, grifos do autor).

Nesse sentido, conforme Betti (1994, p. 42), "o papel do profissional da Educação Física é ajudar a fazer a mediação deste saber orgânico para a consciência, através da linguagem $e$ dos signos".

\subsection{Experiência negativa resultando em fracasso}

O caso de ensino apresentado a seguir, embora tenha sido narrado na $3^{a}$ pessoa, ocorreu com a própria autora da narrativa. Este caso revelou, quando a autora do caso se propôs a escrevê-lo, um grande interesse da parte dela em tornar público e dar visibilidade ao que ela tinha vivenciado.

\section{Trauma de infância!}

Em uma segunda-feira, na aula de educação física, Rúbia² estava animada porque na aula anterior a professora havia dito que iriam realizar algo diferente na próxima aula. Enfim, passaram-se três aulas e chegou a aula de educação física; montou-se uma fila e no centro da fila havia um colchonete. Sem entender o que estava acontecendo os alunos continuaram com muita ansiedade para realizar a atividade, até que o primeiro aluno da fila deitou-se no colchonete e foi ordenado a virar cambalhota e assim fez até que a vez de Rúbia chegou. 0 seu coração foi a mil, ela tremia dos pés a cabeça, e estava quase fazendo xixi nas calças, parece engraçado, mas ela tinha muito medo de fazer esse tipo de exercício, porque a mãe dela já havia alertado de que isso era perigoso e por esse motivo ela nunca tinha feito essa atividade. Como Rúbia era muito dramática ela começou a pensar em todas as consequências enquanto a professora insistia para que ela participasse da aula, até que a professora se cansou de pedir e carregou a aluna à força até o colchonete, deitou-a e mandou que ela levantasse suas pernas e no momento em que levantou, ela puxou-a com força até que fizesse a menina virar para o outro lado. A aluna machucou o pescoço, e com muita vergonha por ter sido a única com dificuldade nessa atividade tão simples, conteve o choro e a dor. Mas ao chegar em casa o pescoço doía mais ainda, então ela contou tudo para sua mãe. Angela, muito nervosa com a situação, disse para a filha que no dia seguinte iria até a escola conversar com a professora, mas a menina não deixou, disse que não tinha outra forma, que ela teria que realizar o exercício de qualquer modo, pois a professora era muito rígida. Até hoje Rúbia odeia essa aula, e não participa dos exercícios de forma alguma, mas não por culpa dos profissionais que exercem essa profissão, e sim por culpa de uma única pessoa!

Ocaso em sijá explicita uma experiêncianegativa, pois aponta em seu final o afastamento da aluna "dos exercícios" de Educação Física. Além da narrativa produzida, quando a aluna respondeu a entrevista, reforçou o quanto esta experiência lhe causou desconforto e resultou numa situação de fracasso, tendo em conta que, depois disso, nunca mais participou das aulas deste componente curricular.

2 Todos os nomes de pessoas e instituições que aparecem nas narrativas são fictícios. 
Quando nos arriscamos em definir o fracasso escolar na Educação Física como aquela manifestação na qual o aluno não se movimenta e não se sente autorizado a expressar seu próprio movimento, encontramos evidências desta proposta de definição no caso em questão, uma vez que a aluna tinha construções culturais acerca do movimento de rolamento que não foram respeitadas/consideradas pela professora. As experiências de movimento são ricas e podem ampliar nossa percepção sobre nós, o outro e o mundo, entretanto, no entorno destas possibilidades existem medos, inseguranças, receios, orientações familiares que, antes de qualquer experimentação, precisam ser conhecidas pelo professor e, mais do que isso, consideradas para qualquer intervenção que ele venha a realizar em suas aulas.

Não se trata aqui de julgar a professora de Educação Física do caso apresentado, mas de alertar outros professores para a culturalidade do movimento, ou seja, ele não se faz num vazio de significados, mas é repleto de histórias que se constroem das infinitas possibilidades e relações humanas.

Outra curiosidade deste caso foi o fato de que, embora reconheçamos que a experiência não possa ser reconstruída (LARROSA BONDÍA, 2002), a reflexão sobre ela, em especial na educação escolar, poderia possibilitar uma reconstrução do seu sentido. Entretanto, este parece não ter sido o contexto da protagonista do caso, na medida em que sua narrativa expressa a continuidade de uma percepção e estabelecimento de sentido. A situação narrada ocorreu na $2^{2}$ série do ensino fundamental, e agora, no ensino médio, portanto, oito anos depois, a aluna ainda não conseguiu participar das aulas de Educação Física. Essa permanência do sentido da experiência vivida ao longo do tempo reforça os apontamentos de Costa (1997), tendo em conta que muitas das resistências, negativas e distanciamentos para com as aulas de Educação Física no ensino médio têm suas origens no ensino fundamental.

\subsection{Experiência negativa resultando em mais participação nas aulas}

No caso de ensino a seguir evidenciamos que, embora a situação tenha sido considerada uma experiência negativa pela aluna, tal vivência marcou de modo positivo sua relação com a Educação Física na escola, aproximando-a muito mais das aulas.

\section{0 preconceito nas aulas de educação física}

A aula começa mais uma vez, numa terça-feira na $8^{a}$ série. A professora Augusta entra na sala, faz a chamada e nos leva para a quadra, lá se dividem os times para se jogar futebol. Cada aluno ia escolhendo os seus times. Os meninos iam escolhendo: 0 Josué, Márcio, Vitor e os outros... Porém, quando a professora Augusta os mandava escolher as meninas para jogar eles sempre achavam ruim. Falavam que nós não sabíamos jogar, que éramos burras e nem sabíamos chutar a bola direito. Mas mesmo assim nós fomos e jogamos. Mostramos para os meninos que não são só eles que sabem jogar bola e sim que somos mulheres de encarar e que também sabemos jogar futebol. Mas sempre eles querem ser os melhores em tudo e que sabem de tudo. Tanto é que até hoje existe este tipo de preconceito nas escolas. E sempre Josué, Márcio, Vitor querem mostrar que são melhores que Paula, Marta, Adriana, mas nós vamos vencer! Com a ajuda de nossa professora Augusta, esse preconceito irá acabar.

Esta narrativa dá relevo a uma situação que se contrapõe à linearidade da ideia de experiência negativa resultando em distanciamento das aulas de Educação Física. A protagonista, autora do caso, identifica a situação vivenciada como uma experiência negativa, 
entretanto, os efeitos desta vivência para as aulas de Educação Física a motivaram mais a participar das aulas e a superar os desafios por ela vivenciados com seus colegas de turma.

A situação foi vivida pela autora na $8^{\text {a }}$ série do ensino fundamental, enfatizando a questão do gênero associada ao conteúdo futebol. As questões relativas às diferenças dos gêneros aparecem constantemente nas aulas de Educação Física e, com muita frequência, indicando os meninos como superiores às meninas, o que critica Martinelli et al. (2006, p. 4), "No entanto, não há nada que garanta que os meninos são mais habilidosos que as meninas ou vice-versa, pois se tratasse de alguma atividade de dança, por exemplo, as meninas teoricamente apresentariam vantagens em relação aos meninos".

Souza e Altmann (1999) convergem com Martinelli et al. (2006) e reforçam que nos esportes, por exemplo, a mulher se manteve por muito tempo como perdedora, pois era denominada como um corpo frágil e delicado, apenas ficando com aqueles esportes que não permitiam contato, ou então aqueles esportes que representavam leveza e docilidade, como 0 voleibol, as danças e as ginásticas.

Como demarcam Souza e Altmann (1999), não podemos afirmar que as meninas são excluídas nas aulas de Educação Física somente pela questão do gênero, uma vez que tal exclusão também envolve o fato de elas serem consideradas fracas e com pouca habilidade. Contudo, essa pouca habilidade ou pouca afinidade com práticas de jogos e esportes está atrelada ao cenário cultural que circunscreve as aprendizagens das meninas, determinando certo modo de sentir, pensar e agir.

Especificamente relacionada a este cenário cultural evidencia-se a masculinização do conteúdo futebol nas aulas de Educação Física. A tradição cultural brasileira que prestigia a prática do futebol para os homens desde bebês nutre uma construção de sentido que invade a escola e que alimenta a resistência dos meninos em jogar com/junto às meninas, naturalizando este ponto de vista como se ele fosse assim desde sempre. Isso acaba valendo tanto para os meninos quanto para muitas meninas que partilham desta naturalização aceitando, sem resignação, o cumprimento dessa "regra".

Nesta perspectiva, podemos destacar a importância que os alunos dão às experiências nas aulas de Educação Física nas quais eles são aceitos pelos colegas do grupo escolar, participam dos jogos e são considerados habilidosos e bem-sucedidos pelos pares nas aulas de Educação Física. Muitas vezes, os sentimentos e desejos construídos por meio dessas experiências passam despercebidos pelos professores. Essas questões precisam ser dialogadas entre educador e educandos ao longo das aulas, gerando experiências e reflexões que deem condições de os alunos construírem outras referências no campo dos valores e das atitudes.

Isso quer dizer que uma experiência considerada pelo(a) aluno(a) como negativa nem sempre conduz a uma relação de afastamento das aulas de Educação Física. Tal identificação atribui destaque à dinâmica da reflexão sobre a experiência, bem como ao seu compartilhamento entre alunos e professores, na medida em que pode possibilitar a circulação e a produção dos saberes escolares (MARIEL RUIZ, 2010).

\subsection{Experiência positiva resultando em mais participação nas aulas}

Para o caso a seguir, a experiência do jogo de basquetebol assumiu um significado muito positivo para a aluna, revelando que nem sempre é na vitória, na superioridade 
demonstrada no jogo ou na marcação de pontos ou gols que a satisfação e o interesse do aluno se estabelecem, mas em situações como de participação e desafio proporcionadas aos alunos pelo próprio jogo que geram sentimentos de autossuperação, diversão e bem-estar.

\section{Basquete!}

Era uma atividade elaborada pelo governo que dizia que todos tinham que jogar basquete. Todos jogaram e foi bem emocionante! Eu não havia jogado ainda $\mathrm{e}$ quando joguei foi legal. No começo achei muito sem graça, pois eu não gostava, depois com o decorrer da aula foi ficando mais legal. A aula foi elaborada pela proposta de ensino que o governo mandou para a escola, a professora Tânia de educação física seguiu todos os padrões e foi bem divertido. O Rafael que sabia jogar melhor que muitos se sobressaiu mais, ele ficava com a bola quase todos os lances, e sempre passava por todos, ele e o Vinícius que também era muito bom no jogo. Eu não sabia jogar muito bem, mas me diverti muito correndo pra lá e pra cá tentando pegar a bola. Dificilmente eu e minha amiga Alexandra conseguíamos jogar, mesmo assim nós tentávamos. Eu não conseguia fazer cestas, pois eu sou um pouco baixa e a cesta fica alta, mas valeu cada esforço, cada corrida, para no fim dizer que eu consegui jogar! Mesmo jogando errado eu tentei cada lance, correndo de um lado para o outro da quadra eu e o resto da turma. Foi o único ano que pude dizer que eu tive uma aula de educação física decente. Eu gostei muito! Aprendendo que o que eu ganhei naquela aula foi uma grande satisfação, pois no começo era sem graça, mas no fim foi muito boa!

A narrativa apresenta a existência de alunos mais habilidosos para jogar basquete que se destacavam na aula, materializando uma forma de se perceber e agir neste contexto, ainda que se identificasse como uma pessoa que não sabia jogar. Para ela, isso não foi um problema, o fato de ter participado e se divertido no jogo deixou marcas positivas em suas lembranças, uma vez que a experiência ocorreu no 6 을 ano do ensino fundamental, alimentando seu interesse em participar mais das aulas de Educação Física.

Articulando essa impressão da aluna com as proposições de Charlot (2005), podemos dizer que o desafio proporcionado pela experiência mobilizou a aluna para uma situação de aprendizagem, possibilitando que ela atribuísse um sentido positivo associado ao prazer e ao atendimento de um desejo.

O caso de ensino a seguir refere-se a um episódio narrado por uma aluna, ocorrido quando ela estava na $2^{a}$ série do ensino fundamental. Segundo a aluna, o acontecimento, considerado uma experiência de sucesso, a obrigou a aprender a perder, contribuindo de forma positiva para sua participação nas aulas de Educação Física, o que só aumentou a partir de então.

\section{A viagem}

Como sempre, mais um dia de aula na terceira série do ensino fundamental. Eu estava muito nervosa, eu e minha professora Cláudia, porque ia ser nossa primeira viagem. Era um grande dia, cheio de expectativas. Nós estávamos indo para a escola Carlos Drummond de Andrade para participar de uma competição com várias escolas, e quem ganhasse iria levar como recompensa um curso de inglês e espanhol e mais o troféu. Nossa escola ia competir nas modalidades: futebol, vôlei e queimada. Chegando à escola a gente foi se posicionando para começar a competição. Quando tudo começou eu estava muito, mas muito nervosa mesmo por causa do futebol. Nós acabamos perdendo de cinco a um no futebol, mas pelo menos ganhamos o vôlei e a queimada. Mas isso não foi o suficiente para levarmos o troféu para a casa... Nós ficamos em sétimo lugar e no final eu acabei chorando junto com a minha professora... 
Ferreira (2000), refletindo sobre a competição, mostra indícios de que a Educação Física Escolar frequentemente supervaloriza a vitória, principalmente em campeonatos entre escolas. A vitória é tomada como objetivo principal da competição, os que não conseguem vencer provavelmente não sentirão nenhuma satisfação em participar da atividade, e o sentimento gerado pela derrota poderá afetar sua autoestima. Há a necessidade de se resgatar o papel educativo da competição na escola, explorando-a como um meio de incentivo à cooperação e à solidariedade.

Assim, cabe ao professor elaborar estratégias para utilizar a competição no processo ensino-aprendizagem, como, por exemplo: modificar as regras da competição, alterar a concepção de "campeonato" para "festival", valorizar os resultados das equipes e não resultados individuais, premiar todos os participantes, dentre outras estratégias. Desta forma, concordando com Ferreira (2000), a competição pode ser canalizada para a lealdade, generosidade, coletividade e respeito para com o adversário.

Num outro caso de ensino, intitulado "Basquete", é apresentado um episódio que ocorreu na mesma escola em que estuda a narradora, quando cursava a $5^{\text {a }}$ série do ensino fundamental. A situação foi de sucesso na visão da aluna, pois "tudo o que aconteceu me ensinou muitas coisas pra minha vida", ressaltou. Essa experiência ainda trouxe contribuições positivas, motivando sua participação nas aulas.

\section{Basquete}

Eu estava na $5^{a}$ série. Nunca gostei de educação física até aquele dia. Meu professor queria fazer algo diferente e o esporte escolhido foi o basquete. Joguei pela primeira vez e não gostei muito, mas nas outras aulas fui gostando. Foi quando o professor me chamou para treinar no time de basquete da escola, e eu fui. No primeiro campeonato que participei não joguei muito porque era nova e 0 time também era muito novo e acabamos perdendo e voltamos muito tristes. No ano seguinte eu comecei a treinar em outro time onde as meninas representavam 0 time da cidade. Neste mesmo ano fui para outro campeonato e o meu time ganhou. Neste campeonato, escolar, aconteceu o pior comigo: quando eu corria para a cesta, uma menina me empurrou e eu bati o joelho no chão, me machuquei e tive que fazer fisioterapia para voltar a correr. Em 2009 voltei a jogar, mas não pelo mesmo time por causa do meu joelho, mas jogava na escola e no campeonato ganhamos medalha de bronze, e foi quando uma ex-jogadora da seleção brasileira me chamou para jogar no time dela. Com ela ganhamos uma medalha de ouro no campeonato regional, uma de prata no estadual e fui indicada como melhor jogadora da liga, mas por alguns pontos não ganhei. Também ganhamos $01^{\circ}$ lugar no inter-escolas. Mas em dezembro de 2010 machuquei o joelho de novo e não pude mais jogar, e por ter 16 anos não posso mais jogar pelo time da cidade, pois não tem o time juvenil, então não jogo mais. Mas foi pela aula de educação física que conheci ex-jogadores da seleção brasileira, conheci várias cidades e muitas pessoas, e uma experiência inacreditável. E hoje posso falar que o meu time de basquete se tornou uma família para mim e me ensinou a me preocupar com 0 próximo e trabalhar em grupo.

A materialização da vivência primeira com o basquete se deu na aula de Educação Física, uma experiência que, segundo a aluna autora do caso, nem era do seu interesse, tendo em conta que até aquele momento ( $5^{\underline{a}}$ série do ensino fundamental) ela não gostava das aulas de Educação Física.

O caso também manifesta que o contato com o conteúdo basquetebol não foi prazeroso ou interessante para a estudante logo no começo, mas passou por um processo de afetividade 
ao longo das percepções e sentidos que foram sendo construídos pela aluna neste tempo: "Joguei pela primeira vez e não gostei muito, mas nas outras aulas fui gostando".

A narrativa expressa a temporalidade da experiência, ou seja, o processo vivido nem sempre tem um efeito imediato, mas vai se construindo ao longo do tempo, agindo como uma matriz inicial de possibilidades e se reconfigurando em aprendizagens. Como defende Larrosa Bondía (2002), a experiência precisa de tempo para acontecer, e é por seu intermédio que 0 silêncio e a memória agem na mobilização das coisas que nos acontecem, nos formando e nos transformando.

\section{PONDERAÇÕES FINAIS}

Nas articulações entre as experiências e seus impactos para os alunos nas aulas de Educação Física, percebemos como tais situações são permeáveis, na medida em que não se sustentam por uma linearidade, permitindo ajustes e composições diversificadas. Como propõe Mariel Ruiz (2010), a construção de uma pedagogia que reconheça as peculiaridades do sujeito que aprende não pode fugir do desafio das constituições da corporeidade que são particulares, fluidas e móveis, portanto, marcadas pelas experiências que nos acontecem. Neste sentido, as experiências narradas pelos alunos trouxeram indagações aos professores de Educação Física no sentido de mobilizar o saber orgânico para um saber verbalizado, constituindo com isso uma pedagogia que reconheça efetivamente a experiência discente como um saber.

Compreendemos, por fim, que, ao valorizarmos as experiências dos alunos e os sentidos atribuídos às histórias vividas, ao concebermos os casos de ensino como fonte de conhecimento (SCOTT, 2001), tivemos a condição de potencializar a capacidade de formação e ou transformação que são próprias da experiência (LARROSA BONDÍA, 2002), contribuindo para produzir reflexões a respeito das ações pedagógicas na formação do aluno e para ampliar as possibilidades de compreensão e reconstrução de práticas educativas nas aulas de Educação Física.

\section{REFERÊNCIAS}

BETTI, Mauro. O que a semiótica inspira ao ensino da educação física. Discorpo, São Paulo, n. 3, p. 25-45, 1994.

BOGDAN, Robert; BIKLEN, Sari. Investigação qualitativa em educação. Porto: Porto, 1994.

BRACHT, Valter. A prática pedagógica da educação física: conhecimento e especificidade. In: BRACHT, V. Educação física \& ciência: cenas de um casamento (in)feliz. ljuí: Ed. UNIJUÍ, 1999, p. 41-54.

CHARLOT, Bernard. Relação com o saber, formação dos professores e globalização: questões para a educação hoje. Porto Alegre: ArtMed, 2005.

DOMINGO CONTRERAS, J. Ser y saber de la formación didáctica del professorado: uma visón personal. Revista Interuniversitaria de Formación del Professorado, Madrid, n. 68, v. 24, n. 2, p. 61-81, 2010.

FERREIRA, Marcos Santos. A competição na Educação Física Escolar. Motriz, Rio Claro, v. 6, n. 2, 
GALVÃO, Cecília. Narrativas em Educação. Ciência \& Educação, Bauru, v. 11, n. 2, p. 327-345, 2005.

LARROSA BONDÍA, Jorge. Experiência e alteridade em educação. Revista Reflexão e Ação, Santa Cruz do Sul, v. 19, n. 2, p. 4-27, jul./dez. 2011.

LARROSA BONDÍA, Jorge. Notas sobre a experiência e o saber de experiência. Revista Brasileira de Educação, Rio de Janeiro, n. 19, p. 20-28, 2002.

MARIEL-RUIZ, Alejandra. Volver a pensar la pedagogía de la educación física escolar: experiencia, saber y práctica pedagógica. Pensar a Prática, Goiânia, v. 13, n. 1, p. 1-13, 2010.

MARTINELLI, Camila Rodrigues et al. Educação Física no ensino médio: motivos que levam as alunas a não gostarem de participar das aulas. Revista Mackenzie de Educação Física e Esporte, São Paulo, v. 5, n. 2, p. 13-19, 2006.

NONO, Maévi Anabel; MIZUKAMI, Maria da Graça Nicoletti. Formando Professoras no ensino médio por meio de casos de ensino. In: MIZUKAMI, M. G. N.; REALI, A. M. M. R. (Org.). Aprendizagem profissional da docência: saberes, contextos e práticas. São Carlos: EdUFSCar, 2002. p. 139-160.

NUTTI, Juliana Zantut; REALI, Aline Maria de Medeiros Rodrigues. Superação do fracasso escolar, políticas públicas e classe de aceleração. In: MIZUKAMI, M. G. N.; REALI, A. M. M. R. (Org.). Aprendizagem profissional da docência: saberes, contextos e práticas. São Carlos: EdUFSCar, 2002. p. 21-47.

PERRENOUD, Philippe. Ofício de aluno e sentido do trabalho escolar. Porto: Porto, 1995.

REIS, Pedro. As narrativas na formação de professores e na investigação em educação._Nuances: estudos sobre Educação, Presidente Prudente, v. 15, n. 16, p. 17-34, 2008.

SCOTT, Joan W. "Experiencia". La Ventana, Guadalajara, n. 13, p.42-73, 2001.

SOUSA, Eustáquia Salvadora; ALTMANN, Helena. Meninos e meninas: expectativas corporais e implicações na educação física escolar. Cadernos CEDES, Campinas, v. 19, n. 48, p. 52-68, 1999.

ZABALZA, Miguel Angel. Diários de aula: um instrumento de pesquisa e desenvolvimento profissional. Porto Alegre: Artmed, 2004. 
Apoio: Pesquisa financiada pela FAPESP - Bolsa de Iniciação Científica.

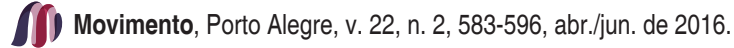

